\title{
ANALISANDO OS CONCEITOS DE RENDA DA TERRA E VALOR DO SOLO A PARTIR DA LÓGICA DA ESPECULAÇÃO IMOBILIÁRIA: UM ESTUDO SOBRE O MUNICÍPIO DE BARRA DOS COQUEIROS/SE
}

\author{
Luiz André Maia Guimarães Gesteira \\ Universidade Federal de Sergipe \\ Programa de Pós-Graduação em Geografia Campus de São Cristóvão (SE), Brasil \\ andre maiageoufs@yahoo.com.br
}

\begin{abstract}
RESUMO
Buscou-se ao longo desse artigo discutir a teoria marxista da renda da terra a partir do processo de produção do espaço no município de Barra dos Coqueiros/SE, planejado pelo Estado para atender às demandas da indústria do turismo e do mercado imobiliário. Para isso, além de extensa pesquisa bibliográfica, foi realizado um prolongado trabalho de campo que permitiu a escrita da dissertação de Mestrado que motivou este artigo. Os conceitos de renda absoluta, renda diferencial e renda de monopólio, em conjunção ao conceito de valor mostraram-se de grande utilidade para a compreensão da lógica de funcionamento da especulação imobiliária enquanto estratégia do capital financeiro, visando o ajuste espacial capitalista em sua busca incessante por novos espaços de reprodução do capital. Evidenciando que a teoria da renda da terra, originalmente formulada para compreender as relações estabelecidas pelo capital no espaço agrário, mostra-se, com as devidas adequações, também fundamental para a discussão sobre sua expansão sociometabólica no espaço urbano.
\end{abstract}

Palavras-chave: Renda Diferencial. Valor. Apropriação Privada do Espaço. Mercado Imobiliário. Urbanização.

\section{ANALYZING THE CONCEPTS OF RENT OF THE LAND AND VALUE OF THE SOIL FROM THE PROPERTY SPECULATION LOGIC: A STUDY ON THE MUNICIPALITY OF BARRA DOS COQUEIROS/SE}

\begin{abstract}
It was sought throughout this article, to discuss the Marxist theory of rent of land starting of the space production process in the municipality of Barra dos Coqueiros/SE, planned by the State to meet the demands of the tourism industry and the property market. For this, in addition to extensive bibliographical research, a long fieldwork was performed that allowed the writing of the Master dissertation that motivated this article. The concepts of absolute rent, differential rent and monopoly rent, in conjunction with the concept of value, have proved to be very useful for understanding the logic of the functioning of property speculation as a strategy of financial capital, aiming the capitalist spatial adjustment in its ceaseless quest for new spaces of reproduction of capital. Evidencing that the theory of rent of land, originally formulated to understand the relations established by capital in the agrarian space, is shown, with appropriate adjustments, also fundamental for the discussion about the sociometabolic expansion of capital in urban space.
\end{abstract}

Keywords: Differential Rent. Value. Private Appropriation of Space. Housing Market. Urbanization.

\section{INTRODUÇÂO}

Marx (1985), ao escrever sua teoria sobre a renda da terra no final do século XIX - na verdade uma crítica e um salto qualitativo em relação aos escritos de Adam Smith e David Ricardo, datados do final do século final XVIII e início do século XIX, respectivamente - formulou alguns conceitos fundamentais para o entendimento da relação que se estabelece entre o processo de expansão do modo capitalista de produção e a propriedade privada de grandes áreas de terra, mantidas, na

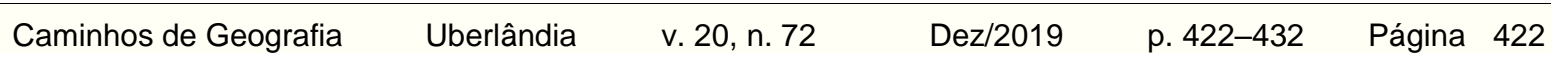


Europa àquela época, nas mãos de uma aristocracia remanescente do sistema feudal, mesmo com o advento e consolidação do capitalismo.

Essa propriedade mantida ainda sob o poder da aristocracia passava a se configurar com o surgimento e expansão do modo capitalista de produção como um óbice à reprodução do capital, uma vez que os antigos senhores de terras não realizavam a extração do mais-valor diretamente a partir delas, e, por sua vez e em contrapartida, os novos empreendedores capitalistas necessitavam naquele tempo histórico do usufruto dessas mesmas terras na perspectiva de garantir a expansão da acumulação do capital a partir da exploração da força de trabalho que nelas seria realizada.

No intuito de superar a contradição estabelecida entre propriedade privada da terra e capital, se estabelece uma aliança entre proprietários e capitalistas na qual estes últimos assumem a função de arrendatários, passando a pagar um tributo aos senhores de terras para usufruir destas, e assim, consequentemente, garantir a retirada de lucro a partir da exploração do trabalho. Esse tributo, que na verdade não era pago pelo capitalista, mas pelo trabalhador por ele empregado e do qual ele extraia o mais-valor na produção agrícola, recebe o nome de renda da terra. Essa renda, no entanto, tende a sofrer certas variações, tanto de acordo com uma série de especificidades do solo que é arrendado, como também de acordo com o que nele é produzido.

Para melhor explicar a relação acima descrita, Marx (1985) elabora - ou reelabora - os conceitos de renda diferencial, renda absoluta e renda de monopólio, os quais podem, apesar das distinções entre a realidade material na qual a sua teoria foi formulada e o processo de produção do espaço urbano analisado ao longo desse artigo, ser sobremodo utilizados para uma melhor análise da lógica da especulação imobiliária e do processo de valorização do solo viabilizado a partir da expansão urbana.

$\mathrm{Na}$ formulação da teoria da renda da terra, o autor alemão trabalha com destaque o conceito de renda absoluta, que seria a porcentagem da renda paga ao proprietário unicamente pelo uso da terra, e que seria paga em qualquer situação, independente da localização ou da qualidade do solo apropriado pelo arrendatário. A renda absoluta se materializa, então, unicamente em razão de o senhor da terra deter o poder sobre a propriedade privada desta, o que the daria o direito de cobrar um tributo pelo seu uso. Assim, o fato de possuir a terra, por si só, já garante uma renda a um grupo privilegiado de pessoas, que independente da forma pela qual a conquistaram, podem cobrar daquele que a arrenda e consequentemente de todo o conjunto da sociedade um valor por aquilo que nela é produzido, mesmo que estes proprietários não façam necessariamente parte do processo produtivo.

Outro conceito de grande importância na teoria da renda da terra e que será prioritariamente tratado ao longo desse artigo é o da renda diferencial, a qual pode ser compreendida através da retirada de um lucro suplementar por parte do arrendatário, em decorrência de utilizar terras mais férteis ou com quaisquer outras condições que facilitem e/ou valorizem a produção a ser realizada. Uma vez que o preço médio regulador da produção é determinado de acordo com as condições materiais de produção nas piores terras, o arrendatário que detém o usufruto das melhores áreas obtém dessa forma um lucro suplementar em relação àqueles que realizam sua produção em terras de qualidade inferior. Nesse sentido, a renda diferencial é um pagamento suplementar ao proprietário por parte do arrendatário, em face do lucro obtido por este por usufruir de melhores áreas, as quais beneficiam a atividade econômica realizada. Destaca-se, no entanto, que também esse lucro só é possível graças à exploração do trabalho, raiz de todo o capital. Em suma, levando em conta o arrendamento de áreas de proporções similares, aquelas onde as condições naturais oferecem maiores vantagens aos investimentos do arrendatário ou ainda aquelas que por algum outro motivo são sobrevalorizadas, tendem a "cobrar" um preço maior ao capitalista para que este possa delas usufruir.

A renda de monopólio, por sua vez, pode ser obtida em situações nas quais o usufruto de uma determinada área possa conferir a quem a usa, condições especiais - quase que sui generis - que a diferencia das demais, garantindo que o controle sobre o monopólio do seu uso permita vantagens únicas ao usuário. Nesse caso, observa-se não apenas diferenciais positivos - como no caso da renda diferencial - em relação às áreas de onde é retirado o preço médio regulador, mas, condições que permitem ao usuário dessas terras retirar vantagens exclusivas do seu usufruto. No caso do espaço agrário observa-se que situações como o acesso a determinados tipos de solos raros, nos quais mercadorias supervalorizadas podem ser produzidas, ou o acesso na própria propriedade a fontes de água essenciais à produção podem configurar um tipo de renda de monopólio.

Antes de iniciar-se a discussão sobre a renda da terra no espaço urbano, faz-se necessário destacar que os investimentos do capital financeiro em áreas com essas características permitem formas de extração de renda inovadoras, sobretudo porque o próprio capitalista passa a fazer às vezes também

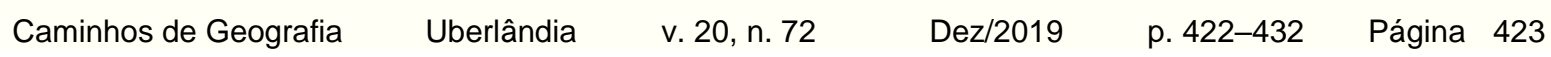


de proprietário, extraindo renda tanto de quem procura uma parcela do espaço para a produção como também de quem dele necessita para a própria existência. Dessa forma os promotores do mercado imobiliário destinam em seus empreendimentos áreas voltadas para o setor de serviços, que podem ser alugadas para os mais diversos fins, e são sobrevalorizadas tanto pela localização como pelo entorno do próprio empreendimento, e que além de tudo garantem ao locatário um mercado consumidor intramuros, sobrevalorizando assim o fator diferencial e a extração de tal renda.

Nesse caso específico, observa-se o capitalista cobrando renda de outro capitalista, o qual certamente também explora força de trabalho para a extração de mais valor. Além disso, tanto o setor hoteleiro como também o de imóveis alugam áreas destinadas ao turismo e ao lazer em seus empreendimentos, extraindo renda diferencial por conta também da localidade, mas sobremodo pela potencialização do valor agregado ao espaço produzido pelo trabalho social. Em ambos os casos o que existe é a prestação de um tributo pelo usufruto de um espaço de acordo com suas características naturais e também pelas socialmente produzidas, ou seja, renda (em suas diversas formas) acrescida de valor, independentemente de qual o usufruto destinado à parcela do espaço pelo qual se paga a renda.

Já no caso da compra de imóveis, o capitalista cobra um preço pelo acesso à terra que ele, via de regra, subdividiu em lotes, potencializando os diferenciais e o valor que é incrementado através do trabalho social, extraindo taxas de lucro exorbitantes com a venda, justamente por conta da renda diferencial e pelo valor agregado na produção do espaço. Enquanto isso, há também a retirada de lucro pelo capital financeiro em cima de juros de financiamento que só existem por causa da necessidade de acesso à terra para moradia. Por fim, outro fator que intensifica a acumulação de capital é a verticalização dos imóveis, que ademais supre parcialmente também o obstáculo da raridade do solo em áreas onde se pode extrair renda diferencial voltada ao mercado imobiliário com forte atrativo ao turismo. Ou seja, é possível às construtoras e demais agentes do mercado imobiliário extrair sobrelucro em uma mesma parcela do espaço, especialmente quando esta conta com fatores diferenciais de valorização.

\section{RESULTADOS E DISCUSSÃO}

Avaliando que a partir da compra ou do aluguel de determinada área do espaço urbano, o locatário ou comprador tende também a pagar um preço pelos diferenciais existentes, sobretudo quando os mesmos permitem algum tipo de vantagem única que será obtida por ele, abre-se a discussão sobre os aspectos que denotam a qualidade e o preço da terra urbana, essenciais à especulação imobiliária, destacando também a importância desse mercado na lógica da expansão da acumulação, uma vez que na contemporaneidade "Los especulativos mercados inmobiliarios urbanos se han convertido em los principales motores de la acumulación de capital" (HARVEY, 2007, p. 164). Para isso, discutir-se-á a lógica da especulação imobiliária de acordo com a análise de características espaciais que podem ser mais bem observadas precisamente quando insere-se os conceitos de renda diferencial e de monopólio para compreender tal dinâmica.

Observa-se que o mercado imobiliário tende a valorizar alguns aspectos que até mesmo dentro da dinâmica urbana tendem a parecer contraditórios. Enquanto áreas em localizações centrais e próximas às grandes aglomerações caracterizam-se, em geral, por serem valorizadas, com esse sendo um diferencial sobremodo positivo no setor de serviços e em variados tipos de indústrias. $O$ mercado imobiliário pode apresentar padrões distintos até mesmo no que é imanente à sua própria lógica interna, que em determinados perfis de empreendimentos pode valorizar tal característica de centralidade, enquanto em outros, esses mesmos aspectos podem ser avaliados como prejudiciais aos anseios do mercado. Como por exemplo, quando há uma clientela que busca especificamente exclusividade e auto-segregação, caracterizando assim um certo distanciamento das áreas centrais como importante fator de valorização.

Esse padrão de relativo distanciamento dos centros das cidades, por exemplo, é bastante comum em grandes cidades, nas quais pessoas com maior poder aquisitivo intensificaram nas últimas décadas um processo de ocupação de espaços "periféricos" privilegiados, afastando-se das grandes aglomerações, e, por conseguinte, conferindo a áreas com esse perfil um novo padrão de valorização. Nesse sentido, localizações que mantenham certa proximidade das áreas centrais, sem necessariamente sofrer com as vicissitudes de fazer parte destas, tendem a desenvolver na lógica atual do mercado de imóveis voltado aos condomínios fechados de luxo, um padrão de renda diferencial, levando em conta justamente esse tipo de demanda.

\begin{tabular}{|c|c|}
\hline Caminhos de Geografia & Uberlândia $\quad$ v. 20, n. 72 \\
\hline
\end{tabular}


Observa-se, dessa forma, que o fator localização pode indicar distintas possibilidades, dependendo do que venha a ser o diferencial positivo que se busca na apropriação e usufruto do espaço. Nesse sentido, os efeitos da aglomeração podem ser positivos ou negativos ao mercado imobiliário, todavia, o capitalista - construtoras, incorporadoras e demais especuladores do mercado imobiliário - sabe lidar com essas distinções, retirando lucro em cima de fatores de renda diferencial ou até mesmo de monopólio de cada área de acordo com o potencial que nela existe e com as adequações mais convenientes à ampliação da acumulação. Trata-se para o capitalista individual, então, de trabalhar a potencialidade já existente nas localizações - seja esta natural ou já produzida socialmente em períodos anteriores - e ao mesmo tempo continuar a produzir o espaço de acordo com as necessidades de acumulação de cada tempo histórico e parcela do espaço geográfico. Os diferenciais positivos já previamente existentes na lógica do espaço urbano podem então tanto ser naturais como também aqueles outrora já produzidos pelo trabalho social.

Outro ponto relevante quando se faz referência à especificidade do especulativo mercado imobiliário é que a constante necessidade por novas parcelas do espaço disponíveis ao processo de acumulação faz com que a propriedade privada da terra se configure em um óbice ainda maior a este mercado do que o é às demais formas de reprodução do capital no espaço urbano, assim como o é também incomparavelmente superior ao que representava à expansão capitalista no espaço agrário estudado por Marx (1985). No mercado da construção civil cada parcela do espaço produzida - ou seja, onde é construído um imóvel residencial - não pode, via de regra, ser doravante aproveitada visando uma produção contínua dentro da lógica produtiva do capital, e mesmo ainda o processo de verticalização na construção de imóveis possuí suas limitações. Há assim, frente à raridade do solo urbano, uma verdadeira emergência do mercado imobiliário pela incessante apropriação e contínua produção de "solo novo".

Dessa forma, por mais que o advento do modo capitalista de produção tenha gradativamente mudado o foco da propriedade imobiliária (a terra) para a propriedade mobiliária (o dinheiro), observar a primazia da propriedade privada no modo de produção hegemônico é fundamental para analisar a reprodução do capital, pois a preponderância pela apropriação do espaço a partir da propriedade da terra não só persiste como se consolida a partir das contradições do capitalismo, que mesmo em momentos em que pareceu necessitar suprimi-la acabou por valorizá-la. O que deixa evidente que o radicalismo liberal (burguês) da Belle Époque, que tinha o intuito de suprimir a propriedade privada da terra e aniquilar a velha classe dos proprietários fundiários (LEFEBRVE, 1999, p.160), nem sequer se aproxima do seu intento "revolucionário". Pelo contrário, a propriedade privada e até mesmo a aliança de interesses entre os investidores capitalistas e a aristocracia agrária foram condição sine que non para o processo histórico de ampliação da acumulação de capital.

Voltando à distinção entre a apropriação do espaço nas lógicas dos capitais fundiário, industrial e financeiro (imobiliário), observa-se ainda que, enquanto a produção agrícola pode usar uma mesma área do espaço de forma contínua para, safra após safra produzir alimentos, e a própria indústria pode produzir manufaturas continuamente também em uma mesma área do espaço; no mercado imobiliário, o próprio espaço é a mercadoria a ser comercializada, por isso há uma demanda infindável por terra e por produção do espaço. Uma vez vendida uma determinada área do solo urbano, é necessário urbanizar novas áreas para continuar o processo de reprodução do capital em ritmo acelerado. Assim, tanto os ajustes espaciais capitalistas - na perspectiva de preparar novas áreas para a expansão do capital financeiro - como o processo de destruição criativa que induz à obsolescência planejada do espaço, destruindo áreas já produzidas socialmente para produzir um novo espaço em uma mesma área - sobretudo a partir da gentrificação - são fundamentais para esse mercado, com frequente necessidade de expansão. E, em ambos os casos a participação do Estado é essencial para possibilitar a materialização desses processos, que visam fundamentalmente impedir que a raridade do solo urbano se torne um entrave ao giro de rotação do capital.

Essa mudança incessante rumo a um 'ajuste espacial', referente às contradições internas do capitalismo, junto com a inserção desigual de diversos territórios e formações sociais no mercado mundial capitalista, criaram uma Geografia histórica global da acumulação do capital (HARVEY, 2005, p.193).

No cerne das contradições do modo capitalista de produção, o mercado imobiliário se relaciona com a perspectiva da raridade do solo urbano de formas distintas. Enquanto, por um lado, necessita continuamente produzir e habilitar novas parcelas do espaço a partir da urbanização para garantir com isso que a raridade do solo urbano provocada pela propriedade privada da terra não impeça a reprodução do capital, se vale ao mesmo tempo dessa raridade para, na perspectiva da oferta e da procura, manter o preço do solo em patamares que garantam altas taxas de lucro em situações

$\begin{array}{lllll}\text { Caminhos de Geografia } & \text { Uberlândia } & \text { v. 20, n. } 72 & \text { Dez/2019 } & \text { p. } 422-432\end{array}$ Página 425


normais, e sobretaxas de lucro quando os bens imóveis negociados se localizam em áreas nas quais se pode cobrar uma renda diferencial ou até mesmo de monopólio, garantindo com isso lucros excepcionais. Lucros esses que só podem ser retirados, no entanto, quando a própria raridade do solo não limita ou até mesmo impossibilita tal perspectiva.

\begin{abstract}
O espaço, enquanto valor, entra no circuito da troca geral da sociedade (produção/repartição/distribuição) fazendo parte da reprodução da riqueza, constituindo-se em raridade. Por outro lado, vivemos, hoje, um momento do processo de reprodução em que a propriedade privada do solo urbano - condição da reprodução da cidade no capitalismo - passa a ser um limite à expansão econômica capitalista. Isto é, diante das necessidades impostas pela reprodução do capital, o espaço produzido socialmente - e tornado mercadoria, no processo histórico - é apropriado privativamente, criando limites a sua própria reprodução. Nesse momento, o espaço, produto da reprodução da sociedade, entra em contradição com as necessidades do desenvolvimento do próprio capital. (CARLOS, 2007, p. 74).
\end{abstract}

Em uma análise in loco do recorte espacial estudado de acordo com a teoria até aqui exposta, discutir-se-á o cenário do processo de expansão urbana via mercado imobiliário no município de Barra dos Coqueiros (Figura 1), localizado no litoral Norte do estado de Sergipe e vizinho à capital do estado, Aracaju. Tal escolha se justifica uma vez que houve nesse recorte espacial nas duas últimas décadas um intenso processo de especulação imobiliária marcado pela construção de uma série de condomínios fechados de "alto padrão", construídos naquele município justamente por conta de seu potencial paisagístico, agregado à possibilidade de apropriação privada da natureza - a partir das "praias privativas" - e, sobretudo graças à proximidade do município com o centro de Aracaju, o que permite, no caso em questão, aliar os benefícios da proximidade com toda a infraestrutura fornecida pela capital, à possibilidade de salvaguardar um ainda alto nível de exclusividade e auto-segregação.

Figura 1 - Mapa de localização da área estudada

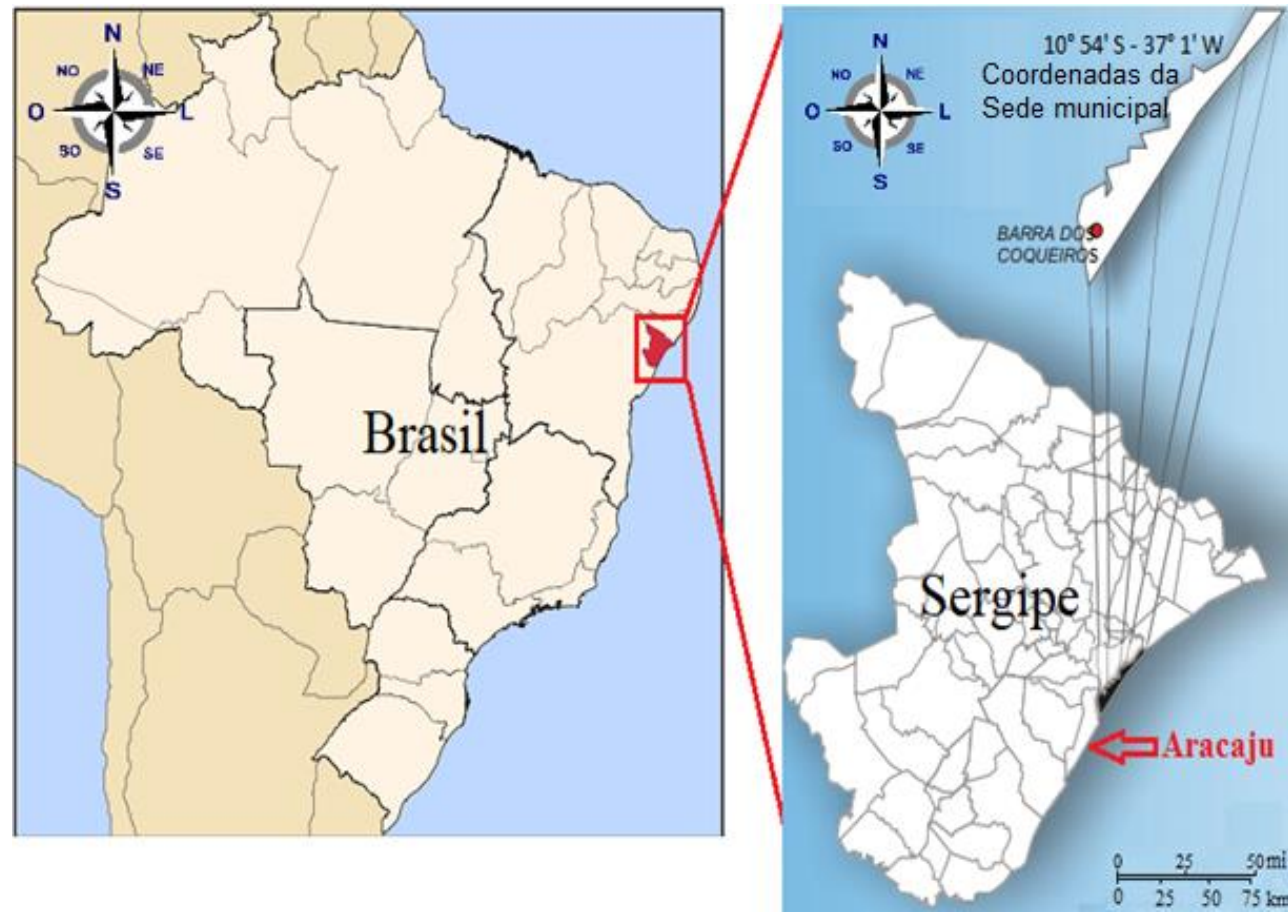

Fonte: CPRM, 2002, Adaptado pelo autor, 2019.

Observa-se nitidamente no cenário estudado a conjunção do potencial paisagístico natural já existente à ação do Estado, que, com a construção da Ponte Aracaju-Barra no ano de 2006 e com ainda outros investimentos no município fomentou decisivamente o turismo e a inserção do mercado imobiliário na região. Assim, Barra dos Coqueiros passou a partir de meados da década de 2000 a contar com diferenciais decisivos para o investimento do capital financeiro em suas terras, somando

$\begin{array}{llllll}\text { Caminhos de Geografia } & \text { Uberlândia } & \text { v. 20, n. } 72 & \text { Dez/2019 } & \text { p. } 422-432 & \text { Página } 426\end{array}$


os aspectos naturais diferenciais já existentes aos socialmente produzidos pelo trabalho humano. Estes últimos, materializados tanto a partir dos investimentos do Estado - como no caso supracitado - quanto através do aporte financeiro dos especuladores do mercado imobiliário.

Constata-se, dessa forma, que as características com potencial para determinar uma renda diferencial ou de monopólio, no que se refere ao mercado imobiliário, podem ser tanto naturais, e nesse caso notadamente aplicáveis aos conceitos (re)formulados por Marx (1985), como podem também ser potencializadas pelo trabalho social, que possuí a capacidade de ampliá-las sobremodo, sem, no entanto desqualifica-las enquanto renda da terra, pois a renda é amplificada pelo trabalho sem, no entanto, deixar de ser renda. O que deixa claro que a lógica de reprodução do capital financeiro no solo urbano possuí importantes especificidades em relação à lógica do capital fundiário no espaço agrário, porquanto no estudo do espaço agrário a terra não é analisada enquanto produto do trabalho e sim como um bem não produzido, como de fato o é, visto que o que se produz no espaço agrário é essencialmente o fruto da terra e não ela própria.

A terra é, pois, um instrumento de trabalho qualitativamente diferente dos outros meios de produção. Quando alguém trabalha na terra, não é para produzir a terra, mas para produzir o fruto da terra. O fruto da terra pode ser produto do trabalho, mas a própria terra não o é. (MARTINS, 1990, p. 159 - 160).

O mercado imobiliário demanda então uma análise diferenciada, já que se desenvolve em um espaço socialmente produzido, usando a terra como condição e não como meio de produção, e retirando, no caso da venda dos bens imóveis, o mais valor de forma definitiva naquela parcela do espaço, e não continuada como ocorre, via de regra, no giro de rotação do capital. No mais, há também de ser lembrada a distinção entre o aluguel e a compra de imóveis. Em ambos o mais-valor do trabalho humano é retirado uma única vez em cada parcela do espaço produzido, mas no primeiro a construção edificada por esse trabalho permite a retirada também do lucro em forma de renda continuamente, enquanto na compra de imóveis isso ocorre em teoria uma única vez, - com um percentual sobremodo mais elevado - podendo em todos os casos ser potencializada por fatores de renda diferenciais ou de monopólio.

O cerne desses conceitos permanece então fundamentalmente presente, uma vez que tanto no que se refere à comercialização de terras para agricultura, como no que se refere à construção civil, um tributo é pago ao proprietário, e havendo diferenciais positivos nessas terras um tributo pelo diferencial ou pelo monopólio que seu usufruto confere é acrescido àquele presente pura e simplesmente pela existência da propriedade privada. Sendo assim, renda absoluta, diferencial e de monopólio fazem parte da lógica do mercado imobiliário antes mesmo da inclusão do trabalho social que acresce valor, potencializando-as.

Dito isto, constata-se que a junção das condições naturais da terra, existente enquanto condição de trabalho, somada ao trabalho social na produção do espaço, vão juntamente definir a qualidade que uma determinada parcela do espaço pode apresentar para a reprodução do capital. Nesse sentido, verifica-se desde áreas que naturalmente já apresentam condições favoráveis à determinada demandas do modo capitalista de produção e consumo, a até outras que podem apresentar condições naturais sobremodo adversas para uma determinada finalidade no processo de expansão da acumulação, e mesmo assim, nestas haver um processo de produção do espaço que lhes confira os requisitos mínimos necessários para os objetivos determinados pelo capital. Como, por exemplo, as áreas dos pôlderes holandeses, que constituem boa parte do território do país, ou, em um exemplo extremamente atual, as ilhas turísticas artificiais construídas em Dubai, nos Emirados Árabes Unidos. Áreas que por suas características naturais jamais poderiam servir aos desígnios que lhes foram definidos, mas que, a partir do processo de produção do espaço foram completamente transformadas pelo homem para suprir às demandas de existência e de produção.

Estes, obviamente, são exemplos extremos, utilizados para demonstrar como não só as condições naturais vão determinar o processo de produção e apropriação do espaço, apesar destas serem decisivas. Todavia, entre uma minoria de parcelas do espaço onde todas as condições são favoráveis à reprodução do capital e outra minoria na qual intervenções drásticas devem ser realizadas para suprir as demandas de expansão da acumulação, existe na maior parte dos casos a necessidade de investimentos e/ou mediações do Estado e do capital na produção do espaço, mas também uma incontestável busca do mercado por áreas que por suas próprias características naturais já permitam que o processo de apropriação do espaço por determinados agentes do capital se territorialize da forma menos dificultosa e com o máximo de possibilidades para a ampliação da acumulação. Tudo isso interfere no quanto uma determinada parcela do espaço será atrativa ao especulativo mercado

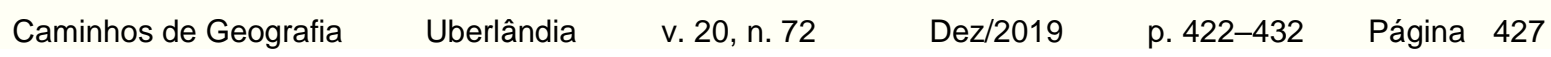


imobiliário, uma vez que quanto maior o trabalho social demandado para produzir uma mercadoria e os gastos para produzi-la, maior valor essa mercadoria tende a possuir. E estes custos, por fim, podem também ser um entrave à comercialização da mercadoria produzida, sobretudo quando a mercadoria é o próprio espaço.

Sendo assim, no mercado de imóveis o preço é uma junção de características naturais/locacionais com o trabalho humano que produz a valorização da terra, sob variados aspectos.

$\mathrm{O}$ desenvolvimento do mundo da mercadoria alcança o continente dos objetos. Esse mundo não se limita mais aos conteúdos, aos objetos no espaço. Ultimamente o próprio espaço é comprado e vendido. Não se trata mais da terra, do solo, mas do espaço social como tal, produzido como tal, ou seja, com esse objetivo, com essa finalidade (como se diz). O espaço não é mais simplesmente o meio indiferente, a soma dos lugares onde a mais valia se forma, se realiza e se distribui. Ele se torna produto do trabalho social, isto é, objeto muito geral da produção, e, por conseguinte, da formação da mais valia (LEFEBVRE, 1999, p 140).

O processo de extração de mais-valor na produção do espaço, no entanto, não se dá como o de uma mercadoria normal. Há nesse caso, além da retirada do lucro sobre o trabalho na comercialização do bem imóvel, a ideia de que a própria produção desse bem, materializada desde a construção dos muros e da infraestrutura da área comum de um condomínio fechado de lotes, a até a edificação de altas torres de prédios, pressupõem uma influência em todo o processo de especulação imobiliária e de produção do espaço contíguo, permitindo a extração de lucros extras de forma continuada a partir das metamorfoses produzidas, que tendem a valorizar o espaço de forma contínua. Sendo assim o trabalho social realizado na produção do espaço não só valoriza a parcela do solo sobre a qual se efetiva, como também valoriza todo o entorno, e esse é um dos grandes potenciais desse mercado, valorizar e valorizar-se enquanto se reproduz.

Por conta disso, os incorporadores e as construtoras agem no sentido de adquirir com grande antecedência extensas áreas de terra, mesmo que as mesmas sejam mantidas muitas das vezes por longos períodos em um letárgico processo de retenção improdutiva, aproveitando-se dessa forma dos preços menos elevados para adquirir os lotes, mantidos como reserva de valor, ou seja, sem nenhum tipo de produção ou função social. Posteriormente, quando surgem condições mais favoráveis para materializar o lucro, aí sim iniciam a construção de seus empreendimentos, em um espaço já repleto da materialização do trabalho social, - seja ele fruto da própria iniciativa privada ou da ação do Estado - ou seja, que já adquiriu um valor propriamente dito a ser agregado.

Dessa forma, em sua necessidade impetuosa pela contínua apropriação do espaço, os promotores do mercado imobiliário se convertem nos principais atores do processo de especulação e valorização das terras, que beneficia também a classe dos proprietários, dentre os quais, beneficiam-se em especial aqueles com maiores áreas e com maior poder aquisitivo, e que tendem justamente por isso a manter por mais tempo suas terras esperando a valorização. A elite desses proprietários, juntamente com os incorporadores e as grandes construtoras mantém uma relação fundamental para o processo de produção do espaço na lógica capitalista, estes últimos em geral com articulação política suficiente dentro do aparelho estatal para garantir que algumas condições determinantes para a ampliação do lucro a partir da especulação imobiliária sejam satisfeitas.

É através da aliança dos proprietários de terras (capital fundiário) com o capital financeiro (representado pelo mercado imobiliário) que pode-se avaliar também algumas das mediações do Estado na produção do espaço. Enquanto nos estudos de Marx (1985) sobre o espaço agrário, os investimentos que promoviam a valorização das terras estavam sobremodo ligados à ação dos arrendatários, e ocorriam basicamente através da melhoria da fertilidade do solo ou da construção de infraestruturas nas áreas arrendadas que maximizassem o lucro na terra, analisada por esse prisma enquanto meio de produção. Quando trata-se do espaço urbano, observa-se uma presença muito mais efetiva do Estado, que media e constrói todo um conjunto de obras infraestruturais, criando com isso condições materiais favoráveis à reprodução do capital, produzindo dessa forma um espaço desigual, que por um lado concebe áreas pensadas desde a sua criação para recepcionar uma ocupação privilegiada, enquanto outras não contam com as mais básicas infraestruturas que permitam a reprodução social dos seus habitantes.

No entanto, mesmo as áreas planejadas pelo Estado-capital e apropriadas pelo mercado imobiliário dentro do atual processo de expansão urbana no município de Barra dos Coqueiros/SE, possuem, ainda entre elas, distintos aspectos definidores da possibilidade de obtenção de renda diferencial por parte capital financeiro. Isso porque identificou-se, de acordo as características naturais e socialmente

\begin{tabular}{llllll}
\hline Caminhos de Geografia & Uberlândia & v. 20, n. 72 & Dez/2019 & p. 422-432 & Página 428
\end{tabular}


produzidas do espaço, assim como de acordo com o perfil dos empreendimentos imobiliários construídos nesse recorte territorial, três distintas áreas de expansão turística e imobiliária (Figura 2), com suas existências atreladas em diferentes medidas à infraestrutura estatal recentemente construída e ao potencial paisagístico local.

A primeira dessas áreas (circulada em marrom) está localizada entre a cabeceira da Ponte AracajuBarra dos Coqueiros e a Rótula de Acesso às Rodovias SE-100 e José de Campos. Nessa parcela do território do município, a grande obra de infraestrutura que deu suporte à expansão imobiliária foi justamente a supracitada Ponte, construída no ano de 2006, e o principal fator diferencial de valorização é a grande proximidade com o centro comercial de Aracaju, que se tornou a partir da construção da Ponte, mais próximo dessa área que as próprias praias do município. Nesse sentido, os empreendimentos imobiliários ali existentes seguem um perfil voltado para um público com menor poder aquisitivo, sendo diagnosticada basicamente a construção de condomínios de prédios de em média quatro andares, com apartamentos em torno de $50 \mathrm{~m}^{2}$, em um perfil bastante procurado por pessoas que trabalham na área central da capital sergipana. Mesmo assim, é importante ressaltar que as construtoras usam também a relativa proximidade com as belas praias do município como fator preponderante na propaganda destes empreendimentos, assim como este o é, seguramente, fator valorização e aferição de renda diferencial por parte do mercado imobiliário também nesse perfil de construções.

Figura 2 - Atributos naturais e disposição espacial da infraestrutura do Estado e da iniciativa privada no estabelecimento da renda diferencial no município de Barra dos Coqueiros/SE

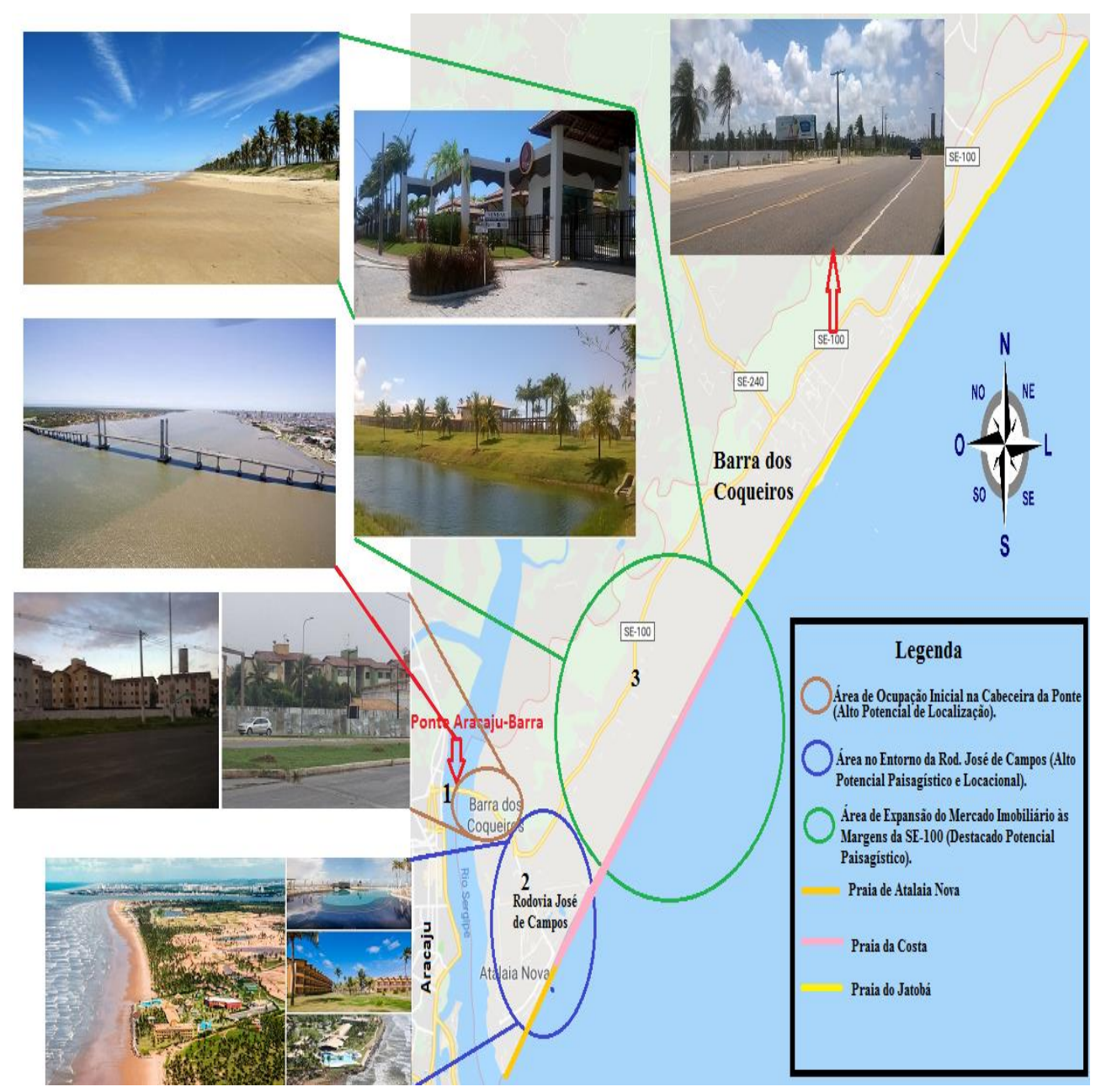

Fonte: Gesteira, 2019. 
A segunda área destacada (circulada em azul), localiza-se ás margens da Rodovia José de Campos e em suas proximidades. Nesse recorte espacial, além da obra de construção da Ponte, destacam-se também os investimentos do governo do estado de Sergipe entre os anos de 2007 e 2010 na revitalização da citada via de acesso às praias do município, que juntamente com as obras realizadas na Rodovia SE-100, representaram um custo de cerca de $\mathrm{R} \$ 21$ milhões em pavimentação e alargamento de suas pistas (Gesteira, 2017). Por agregar a proximidade à Aracaju com o entorno sobremodo atraente ao turismo e ao mercado imobiliário, por conta da presença das belas Praias de Atalaia Nova e da Costa - onde inclusive está localizado o Maikai Resort, maior empreendimento turístico do estado de Sergipe - essa área se destaca como sendo a de maior valorização do solo em todo o município, com inúmeros empreendimentos imobiliários tendo sido construídos ao longo da última década, a exemplo do Costa Paradizo Clube Residenciale, do Damha I Sergipe, do Brisas e do Vida Bela Praia Mar Condomínio Clube e do Complexo Alphaville, com seus três condomínios de grande porte (Alphaville Sergipe, Terras Alphaville Sergipe I e Terras Alphaville Sergipe II), entre outros.

Outro ponto a observar é o tipo de serviços e funções que estarão disponíveis em alguns desses condomínios, que contarão com diversas casas comerciais, escritórios, consultórios, escolas e até mesmo faculdades em seu interior, em áreas arrendadas sob um alto fator de renda diferencial atrelada ao valor agregado no espaço produzido. Um padrão que tende a agravar ainda mais o processo de especulação imobiliária que impulsionou uma valorização do solo "de mais de $300 \% \mathrm{em}$ algumas áreas do município desde o início da década de 2010", conforme informado por um corretor de imóveis que atua no município de Barra dos Coqueiros. Essa valorização fica sobremodo explícita quando constata-se o valor médio de lotes urbanizados em condomínios luxuosos construídos no município, como "o Damha I Sergipe, que conta com lotes de até $R \$ 1,2$ milhão, destinados à construção de mansões de veraneio", ou quando observa-se o valor de "uma casa de $245 \mathrm{~m}^{2}$ no Costa Paradiso Club Residenciale, que pode valer até R $\$ 780$ mil", segundo informou o corretor (Gesteira, 2017).

A área no entorno da Rodovia José de Campos, no entanto, encontra-se já parcialmente saturada pela grande quantidade de condomínios já construídos no local, materializando-se mais recentemente um processo de expansão do capital financeiro para uma terceira área (circulada em verde) que engloba tanto a zona de expansão do município, como parte de seu espaço agrário, abrangendo os Povoados de Olhos D'água e de Capuã, onde considerável número de condomínios fechados de prédios e lotes urbanizados foram e estão sendo recentemente construídos. Nessa parcela do município de Barra dos Coqueiros destaca-se a presença de um perfil de espacialização de condomínios marcado pelo acesso direto à Rodovia SE-100, e ao mesmo tempo pelo acesso "privativo" às praias locais, bem menos movimentadas que a Praia da Costa na Rodovia José de Campos, permitindo assim a materialização do fetiche da praia privativa.

Quanto aos investimentos do Estado em infraestrutura, a expansão do mercado imobiliário nessa área sofre influência tanto da construção da Ponte, quanto das obras de revitalização na Rodovia SE100, fundamentais para facilitar 0 acesso aos empreendimentos imobiliários recentemente construídos. Há, no entanto, uma prevalência nessa área pela busca por fatores de renda diferencial atrelados ao potencial paisagístico local e a um certo grau de auto-segregação, fundamentais ao perfil das mansões de veraneio construídas em alguns dos condomínios ali existentes, a exemplo do Thai Residence e do Maikai Residencial Resort, que leva o "mesmo nome" do maior empreendimento turístico existente no estado. Nesse sentido, a renda diferencial existente por conta dos aspectos paisagísticos naturais é sobremodo preponderante nesse recorte, mas só pode se materializar, por fim, graças às infraestruturas do Estado, em especial a Ponte Aracaju-Barra dos Coqueiros, estopim de todo o processo expansão urbana no município.

Nesse último recorte territorial, entretanto, por tratar-se de uma área que engloba também o espaço agrário do município, há que se destacar que conjuntamente à territorialização dos processos de expansão urbana e especulação imobiliária houve um violento decurso de destruição ambiental, com gravosos rebatimentos na estrutura social das comunidades tradicionais locais. Observando-se que o ímpeto de territorizalização do capital financeiro via indústria do turismo e mercado imobiliário tem fomentado a precarização da vida e do trabalho de dezenas de famílias extrativistas, as quais tiveram sua autonomia cerceada a partir da apropriação de parte considerável das terras do município pelas construtoras e incorporadores, com a consequente derrubada de milhares de exemplares de árvores típicas da restinga, a exemplo da mangabeira, restringindo assim a atividade de "cata" dos frutos pelas comunidades tradicionais locais. Tal processo, que indica ainda a perspectiva de expropriação dessas comunidades frente à impossibilidade de manutenção de sua autonomia, foi

\begin{tabular}{|c|c|c|c|}
\hline Caminhos de Geografia & Uberlândia & v. 20, n. 72 & Dez/2019 \\
\hline
\end{tabular}


possibilitado e subsidiado, sobretudo, pela ação do Estado, não só através da construção de toda a infraestrutura necessária à territorialização do capital financeiro, como também devido à sua omissão na proteção às comunidades tradicionais e ao próprio meio ambiente, através da sustentação do falacioso discurso da urbanização como exclusivo modelo de desenvolvimento.

Assim, a lógica da exploração através da extração da renda da terra, sobremodo potencializada pelo valor do trabalho social na produção do espaço, tem trazido como perspectiva um violento processo de expropriação no município de Barra dos Coqueiros/SE. Frente ao seu potencial cênico e locacional natural, os capitalistas individuais têm conseguido auferir autos índices de renda diferencial urbana na especulação e comercialização de terras, que agregados ao valor intrínseco ao próprio processo de produção do espaço realizado pelo Estado e pela iniciativa privada, possibilitam a eles a retirada de lucros extraordinários. Dessa forma, o giro de rotação que garante a expansão da acumulação pode ser satisfeito, cumprindo assim essa parcela do espaço geográfico seu papel neste tempo histórico para mitigar os efeitos da crise estrutural do capital.

Sendo um modo de controle sociometabólico incontrolavelmente voltado para a expansão, ou o sistema do capital sustenta o rumo de seu desenvolvimento impelido pela acumulação, ou, mais cedo ou mais tarde, implode. (MÉSZÁROS, 2002, p. 131).

De empecilho inicial à expansão capitalista, a extração da renda da terra foi convertida inicialmente em sobretrabalho e "sobreexploração" do trabalhador, para que pudesse ser paga pelo arrendatário ao proprietário (Marx, 1985). Mais recentemente com a conversão do mercado imobiliário em um dos principais motores de expansão da acumulação, ela se torna uma importante estratégia para cobrar de forma diferencial pelo acesso a terra para moradia, comércio, lazer e para toadas as formas de satisfação e fetichização humana, configurando-se como importante força motriz da expansão sociometabólica do sistema do capital, agora sobremodo valorizada pelo trabalho social. Outrossim, o próprio capitalista passa também a converter-se em proprietário e investidor, potencializando a proeminência da propriedade privada para a extração de lucro em múltiplas determinações, valendose para isso, sempre da aliança Estado-capital.

\section{CONSIDERAÇÕES FINAIS}

Lendo o modo capitalista de produção e consumo, ao qual o Estado está em conjunção, como um sistema de exploração geral das qualidades naturais e humanas, que prejudica a adoração da natureza (Marx, apud Harvey, 2005), assim como todas as satisfações tradicionais e as reproduções dos antigos estilos de vida. O qual, em seu superdeterminismo estrutural (Miliband,1970), fluidez e flexibilidade encontra diferentes formas de garantir a sua reprodução sociometabólica, analisa-se a extração da renda da terra com o valor do trabalho social agregado como uma dentre as formas através das quais o mercado imobiliário promove a expansão da acumulação de capital. Por sua vez, o próprio especulativo mercado imobiliário funciona como um preponderante motor da acumulação capitalista, inserido na lógica do capital financeiro, principal estratégia contemporânea de expansão do modo de produção dominante, através da qual o capitalismo busca refrear sua crise estrutural.

Discutiu-se, então, ao longo dessas páginas, um fenômeno manifesto localmente, a partir de uma teoria geral e de uma lógica global, na qual se insere essa parcela do espaço geográfico para a qual os ajustes espaciais do Estado-capital delinearam tal demanda nesse tempo histórico. A renda da terra - em suas distintas modalidades - estudada por Marx (1985), assume então, a partir da lógica estudada, novas nuances no espaço urbano, mas não perde seu core conceitual. Transforma-se ao agregar o valor do trabalho social enquanto fator potencializador, ao concentrar a extração da renda nas mãos do capitalista em detrimento da antiga aristocracia rural, e ao flexibilizar diferentes formas de extração dentro da lógica da indústria do turismo e do mercado imobiliário. Todavia continua sendo uma renda cobrada em virtude da exclusividade da propriedade privada e da necessidade de acesso à terra, uma renda cobrada de distintas formas de acordo com os diferenciais e possibilidades de monopólio que o usufruto da terra pode garantir, e uma renda que no solo urbano, dentro da lógica do espaço mercadoria, enquanto fetiche e relação de poder, mais do que nunca precisa ser estudada.

No capitalismo, como todo o produto da ação humana decorrente do processo de trabalho, o espaço torna-se mercadoria, e nessa condição traz por exigência condições específicas que determinam seu uso e sua forma de acesso; o uso de determinada parcela da cidade requer acesso à propriedade [...] O Acesso a um de seus fragmentos dá trânsito a uma totalidade mais vasta e encerra em si

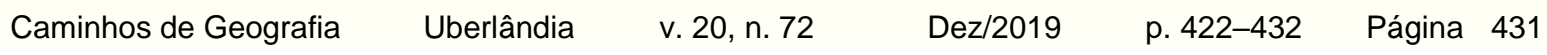


necessidades e desejo; seu uso diferenciado é marcado por relações de poder e propriedade, o que permite atualizar o modo como alienação é vivida na sociedade atual; e, por fim, o acesso diferenciado toma a forma de segregação como produto da justaposição entre morfologia social (condição de classe) e morfologia espacial (lugar que o sujeito ocupa na cidade em função da relação renda/preço do $\mathrm{m}^{2}$ do solo urbano), expressão da realização de uma sociedade de classes fundada na concentração do poder e da riqueza (CARLOS, 2011, p. 92).

Rememora-se, dessa forma, os escritos de Marx (1985), de uma época na qual se iniciou o desarraigamento do homem da terra, a partir dos cercamentos e da própria origem da renda da terra no espaço agrário, que foi também o acentuamento da expropriação e da espoliação do campesinato. Agora presencia-se um processo no qual os aspectos diferenciais naturais, sobremodo importantes para a locação dos empreendimentos imobiliários se unem ao valor do trabalho humano na construção de infraestruturas fora e intramuros, cobrando daqueles que pretendem usufruir desses empreendimentos, pelas características diferenciais locacionais e paisagísticas que lhes são intrínsecas, seja para investir, para produzir ou para viver. Pagam assim os futuros usufruidores desse espaço, renda acrescida de valor para poder estar dentro dos muros que thes permitem desde a privatização da natureza, com suas belas praias e paisagens, a até condições diferenciais de comércio e negócios no interior dos empreendimentos. Mas pagam seguramente muito mais aqueles que estão fora dos muros, os membros das comunidades extrativistas tradicionais locais, que em breve talvez não possam nem sequer olhar esses muros pelo lado de fora.

\section{REFERÊNCIAS}

CARLOS, Ana Fani Alessandri. A Condição Espacial. São Paulo: Contexto, 2011.

CARLOS, Ana Fani Alessandri. O Espaço Urbano: Novos Escritos sobre a Cidade. São Paulo: FFLCH, 2007, 123p.

CPRM - Serviço Geológico do Brasil. Projeto Cadastro da Infra-Estrutura Hídrica do Nordeste: Diagnóstico do Município de Barra dos Coqueiros, Aracaju, 2002.

GESTEIRA, Luiz André Maia Guimarães. A Ação do Estado-Capital na Produção do Espaço e a Expropriação das Comunidades Tradicionais no Município de Barra Dos Coqueiros/Se. Dissertação de Mestrado em Geografia, UFS, São Cristóvão, 2017.

HARVEY, David. A Produção Capitalista do Espaço. São Paulo: Annablume, 2005.

HARVEY, David. Breve Historia del Neoliberalismo. Madrid: Akal, 2007.

LEFEBRVE, Henry. A Revolução Urbana. Belo Horizonte: Editora UFMG, 1999.

MARTINS, José de Souza. Os Camponeses e a Política no Brasil: as lutas sociais no campo e seu lugar no processo político. Petrópolis: Editora Vozes, 1990.

MARX, Karl. O Capital. Livro 3. vol. VI. Trad. Reginaldo Sant'anna. 4 ed. São Paulo: DIFEL, 1985.

MÉSZÁROS, István. Para Além do Capital. São Paulo: Editora Boitempo, 2002.

MILIBAND, Ralph. O Estado na Sociedade Capitalista. Rio de Janeiro: Zahar, 1970.

Recebido em: 01/01/2019

Aceito para publicação em: 12/08/2019 